\title{
Immediate complications and subsequent reproductive outcome after medical abortion: hospital based cross sectional study
}

\author{
Parul Anuj Sathe*, Kamlesh R. Chaudhari, Nirzar Samir Parikh
}

\author{
Department of Obstetrics and Gynaecology,K.J.Somaiya Medical College, Mumbai, Maharashtra, India
}

Received: 29 September 2015

Accepted: 02 November 2015

\author{
*Correspondence: \\ Dr. Parul Anuj Sathe, \\ E-mail: parul.sathe@yahoo.com
}

Copyright: (C) the author(s), publisher and licensee Medip Academy. This is an open-access article distributed under the terms of the Creative Commons Attribution Non-Commercial License, which permits unrestricted non-commercial use, distribution, and reproduction in any medium, provided the original work is properly cited.

\begin{abstract}
Background: Medical abortion is considered to be a safe, effective and reliable method for termination of pregnancy. The procedure has stood the test of time very well over the last 10 years in terms of results and immediate complications but there are not many reports regarding the subsequent reproductive outcome of these women. Thus, it was decided to conduct a study with special focus on subsequent reproductive outcome in women undergoing medical abortion. The objectives of the study were to determine the source of health care provider for women seeking medical abortion, to study immediate complications of medical abortion, to study acceptance of family planning methods post medical abortion in the study subjects and to study subsequent reproductive outcomes in women who underwent medical abortion.
\end{abstract}

Methods: A cross sectional institution based study was conducted after ethics committee approval in the Obstetrics and Gynecology outpatient department of a tertiary care institute from January 2014 to December 2014. 94 newly registered patients in the age group of 18-35 years who came to the Obstetrics and Gynecology OPD during the study period were interviewed. Amongst these those who have undergone medical abortion in the period between 2010 and 2011 and were willing to participate in the study were enrolled. Diagnosed cases of Diabetes Mellitus, Hypertension and any other major medical or surgical illness were excluded from the study.

Study subjects were interviewed with a revalidated, pretested semi structured Questionnaire with due privacy to maintain confidentiality. The data was analyzed by SPSS version 16 software.

Results: $13.8 \%$ study subjects took their medicines from chemists without consulting any medical professional and $9.5 \%$ of them were prescribed these medicines by general practitioners. Prevalence of immediate complications that is incomplete abortion, need for surgical evacuation and excessive bleeding in the study were $17 \%, 11.7 \%$ and $1.1 \%$ respectively. Proportion of women who accepted family planning post medical abortion was $62.8 \%$. Prevalence of subsequent reproductive outcomes in females who did not use permanent method of sterilization or got copper $\mathrm{T}$ inserted were infertility (7.1\%), abortion (8.9\%), ectopic pregnancy (3.6\%), PIH (10.7\%), IUGR (3.6\%) and preterm labour $(10.7 \%)$.

Conclusions: Medical abortion using Mifepristone and Misoprostol is a reliable and safe method of termination of early pregnancy (up to 7 weeks period of gestation). These findings are relevant while counseling patients for medical abortion.

Keywords: Medical abortion, Reproductive outcome, Complications, Family planning

\section{INTRODUCTION}

Despite the fact that contraceptive usage has increased over a period of time, there exists a gap between the knowledge, attitude and practice regarding contraception. ${ }^{1,2}$ Consequently termination of pregnancy is the most common Gynecological procedure. For instance in the US, nearly half of pregnancies are 
unintended and $22 \%$ of all pregnancies end in termination (excluding miscarriages). ${ }^{3}$ Abortion practices have changed dramatically in recent years since the medical method with Antiprogestin - Mifepristone and prostaglandins was introduced. In 2007 in Finland $64 \%$, in Sweden $61 \%,{ }^{5}$ and in the United Kingdom $35 \%$ of all abortions were performed using the medical method. ${ }^{6}$

There are many studies related to medical abortion but focus of most of the previous studies were immediate side effects and complications of medical abortion. ${ }^{7-9}$ There were very few studies in which long term reproductive outcome was studied. ${ }^{10,11}$

The purpose of this cross sectional study was:

1) To determine the source of health care provider for women seeking medical abortion.

2) To study immediate complications of medical abortion.

3) To study use of family planning methods post medical abortion.

4) To study the various reproductive outcomes in women who have taken medical abortion.

\section{METHODS}

The study is a cross sectional institution based study. It was conducted in the Obstetrics and Gynaecology OPD at tertiary care centre in the period from January 2014 to December 2014.

The study was conducted after taking approval from the Ethics Committee.

Newly registered patients who came to the OPD were enquired specifically for history of Medical Abortion. On the basis of their history, patients in the age group of 1835 years (irrespective of the marital status) and who underwent medical abortion in the years 2010 and 2011 were interviewed personally. The purpose of study and responsibility to maintain confidentiality was explained to the subjects. Those who fitted in the above defined inclusion criteria and were willing to participate in the study were enrolled.. Diagnosed cases of Diabetes Mellitus, Hypertension and any other major medical or surgical illness were then excluded from the study. A total of 94 women were enrolled in the study.

The study subjects were then interviewed with pre validated, pretested semi structured questionnaire. The questionnaire included questions pertaining to immediate complications such as excessive bleeding, incomplete abortion, need of surgical evacuation, subsequent reproductive outcomes such as infertility, abortion, and history suggestive of Ectopic Pregnancy, PIH, IUGR and Pre-term Labor and whether family planning method was accepted or not and source of medicine provider (chemist, general practitioner or gynecologist) was enquired.
Appropriate Statistical Test was applied and Data was analyzed by SPSS version 16 software.

\section{RESULTS}

Table 1: Source of healthcare provider for women seeking medical abortion.

\begin{tabular}{|lcc|}
\multicolumn{1}{|c}{ Medicine Provider } & No. of Patients & $\%$ \\
\hline General Practitioner & 9 & 9.5 \\
\hline Chemist & 13 & 13.8 \\
\hline Obstetrician & 72 & 76.5 \\
\hline
\end{tabular}

$23.3 \%$ patients got their medicines from unauthorized sources.

Table 2: Immediate complications of medical abortion.

\begin{tabular}{|lll|}
\hline $\begin{array}{l}\text { Immediate complications (n=94) } \\
\begin{array}{l}\text { Excessive Bleeding (more than } 14 \\
\text { days) }\end{array}\end{array}$ & 1 & $\%$ \\
\hline Retained products of conception & 16 & 1.1 \\
\hline Failed Abortion & 1 & 1.1 \\
\hline Surgical Evacuation & 11 & 11.7 \\
\hline
\end{tabular}

Surgical evacuation was done in $11.7 \%$ of women

Table 3: Family Planning Usage after medical abortion.

\begin{tabular}{|lll|}
\hline \multicolumn{1}{|c}{ Family Planning } & Frequency & $\%$ \\
\hline Yes & 59 & 62.8 \\
\hline No & 35 & 37.2 \\
\hline Total & 94 & 100.0 \\
\hline
\end{tabular}

$37.2 \%$ of women did not use family planning methods

Table 4: Mode of Contraception used after medical abortion.

\begin{tabular}{|lll|}
\hline \multicolumn{1}{|c}{ Mode } & Frequency & $\%$ \\
\hline $\mathrm{Cu}-\mathrm{T}$ & 28 & 47.46 \\
\hline OC Pills & 21 & 35.59 \\
\hline Tubal Ligation & 10 & 16.95 \\
\hline Total & 59 & 100.00 \\
\hline
\end{tabular}

Table 5: Long term reproductive outcome after medical abortion.

\begin{tabular}{|lll|}
$\begin{array}{l}\text { Long term reproductive } \\
\text { outcome }(\mathrm{n}=56) *\end{array}$ & Frequency & $\%$ \\
\hline Infertility & 4 & 7.1 \\
\hline Natural Abortion & 5 & 8.9 \\
\hline Ectopic Pregnancy & 2 & 3.6 \\
\hline Preterm & 6 & 10.7 \\
\hline IUGR & 2 & 3.6 \\
\hline PIH & 6 & 10.7 \\
\hline
\end{tabular}

*Women who underwent Tubal ligation or used $\mathrm{Cu}-\mathrm{T}$ were not included. 


\section{DISCUSSION}

Medical method of termination of pregnancy was found to be a safe, effective and reliable method of pregnancy termination in the study.

$13(13.8 \%)$ of the 94 study subjects took their medicines from chemist without consulting any medical professional and $9(9.5 \%)$ of them were prescribed these medicines by general practitioners. On enquiry they revealed that it is convenient to take from chemist, cheap and also confidentiality is maintained.

9 of the 94 women in our study were unmarried. They had opted for medical method of termination due to various social reasons and they were satisfied with the procedure. 5 of these unmarried women took the medicines from the chemists without consulting any physician and in fact 2 of these were more than 2 months pregnant when they took the pills. One out of these 2 women had to undergo surgical evacuation due to incomplete abortion.

13 patients had their pregnancy beyond 2 months at the time of taking pills for medical abortion. Though there were no significant complications in this group of patients but this number is too small to derive any conclusion. As per the guidelines prepared by WHOCCR in Human Reproduction, All India Institute of Medical Sciences in collaboration with Ministry of Health and Family Welfare, GOI and ICMR; currently the medical abortion in India is approved up to 7 weeks of amenorrhea and only registered medical practitioners as prescribed by the MTP Act are authorized to give drugs for medical abortion. The mean duration of bleeding in our study was 6 days. The duration of vaginal bleeding following medical abortion varies in various studies with a range of 1 to 69 days. ${ }^{8,9,12,13,14}$

The incidence of excessive bleeding in our study was $1.1 \%$. However it is a subjective parameter and the above assessment was on recall basis. One woman gave history of syncope and blood transfusion after taking the medicines. As per literature very rarely (less than $0.2 \%$ ) a blood transfusion is needed after medical abortion. ${ }^{8,15}$ Incidence of excessive bleeding was $15.6 \%$ in a study conducted by Niinimaki et al. ${ }^{16}$ In earlier studies an average of $10 \%$ of women who underwent medical abortion complained of excessive bleeding. ${ }^{17}$

The incomplete abortion rate in our study was $17 \%$. A meta-analysis of medical abortion trials by Kahn and colleaguesreported incomplete abortion rate of $2.9 \% .^{18}$

In our study 16 women had USGs suggestive of incomplete abortion out of which 9 underwent surgical evacuation and 7 were managed medically.

Surgical evacuation subsequent to medical abortion was done in 11 cases $(11.70 \%)$ out of which 9 were for incomplete abortion, 1 was for excessive bleeding leading to syncope and 1 was for failed medical abortion.

Surgical evacuation performed because of incomplete abortion occurred in approximately in $6 \%$ of women having medical termination of pregnancy in a study conducted by Niinimaki et al. ${ }^{16}$

One of these women (1.06\%) had failed medical abortion which was diagnosed on USG done after 15 days of taking pills. She gave history of minimal bleeding after taking pills, no fever, chills, rigor or pain and she had continuing symptoms of pregnancy. She underwent surgical evacuation thereafter. There is a reported incidence of less than $1 \%$ of ongoing pregnancy. ${ }^{15}$

35 women (37.23\%) did not accept any method of contraception in spite of being aware of various contraceptive methods. This shows a big KAP-gap of contraceptive practice in India.

In our study $04(7.1 \%)$ women experienced infertility i.e. they could not conceive spontaneously after 1 year of regular unprotected intercourse subsequent to medical abortion. As per the study conducted by Jacky Boivin et al in 2007 the prevalence of infertility varies from $6.9 \%$ to $9.3 \%$ in less developed nations. ${ }^{24}$ However vast majority of studies, including large populations, have found no association between abortion and subsequent sub-fertility. ${ }^{19}$ Infertility following medical abortion could be the consequence of tubal damage from infection or intra-uterine adhesions secondary to infection.

$2(3.6 \%)$ women out of 94 women had ectopic pregnancy. One population based case control study on risk factors of ectopic pregnancy found a significant increased risk for ectopic pregnancy associated with medical abortion as compared with women with no history of abortion. ${ }^{20,21}$ However, the study included only a small number of women who had a history of medical abortion (13 case patients and 11 controls). Whereas as per a study conducted by Jasveer Virk et al medical abortion as compared with surgical abortion is not associated with increased risk of ectopic pregnancy which is nearly $2.2 \%$ in both. ${ }^{19} 2$ out of these 4 women gave history of IUCD insertion subsequent to medical abortion which can be one of the confounding factors for increased incidence of ectopic pregnancy in our study.

5 out of $94(8.9 \%)$ had spontaneous abortion which indicates that incidence of spontaneous abortion does not rise after medical abortion. Our findings are consistent with the results of study conducted by Virk $\mathbf{J}$ et $\mathrm{al}^{19}$ and a meta-analysis of, ${ }^{12} 484$ cases conducted by GAMC C et al in China. ${ }^{10}$

$14.4 \%$ women had pregnancy induced hypertension and intrauterine growth restriction as against $23 \%$ in general population in India. ${ }^{21}$ Similar results were found in the studies conducted by Virk et and GAM C et al. ${ }^{17,19}$ 
The incidence of preterm labour in the study group was $10.63 \%$. In India the prevalence of LBW has been reported as $26 \% .^{22}$ Our findings on LBW and preterm birth are consistent with the results of a multicentre cohort study from China $^{23}$ which evaluated pregnancy outcome in nulliparous women with no history of induced abortion (4925 women), those with 1 previous Mifepristone induced abortion (4931 women) and those with 1 previous surgical abortion (4800 women). The authors found that a previous medical abortion did not increase the risk of LBW or Preterm birth as compared with no previous abortion or a previous surgical abortion. $^{24}$

This cross sectional study is based on patient's memory and hence there are high chances of recall bias in the study.

Medical abortion using Mifepristone and Misoprostol is a reliable and safe method of termination of early pregnancy (up to 7 weeks period of gestation).

Funding: No funding sources

Conflict of interest: None declared

Ethical approval: The study was approved by the Institutional Ethics Committee

\section{REFERENCES}

1. Charles W, Ann P. Alternative Measure for Unmet Need for Family Planning in Developing Countries. Int Fam Plan Perspect. 2000;7(4):126-35.

2. Ashoke S, John S. and Jayanti MT. The KAP-gap in Nepal: Reasons for non-use of Contraception Among couples with Unmet Need for Family Planning. AsiaPacific Population Journal. 2000;6(1):25-38.

3. Jones RK, Zolna MR, Henshaw SK, Finer LB. Abotion in the United States: incidence and access to services, 2005. Perspect Sex Reprod Health. 2008;40:6-16.

4. National institute for Health and Welfare: Induced abortions. Available at: Retrieved 2009.

5. The National Board of Health and Welfare. 2009.

6. Department of Health. 2009.

7. Grimes DA, Risk of Mifepristone abortion on context. Contraception. 2009;71:161.

8. Thong KJ, Bair DT. Induction of abortion with Mifepristone and Misoprostol in early pregnancy. $\mathrm{Br}$ J ObstetGynaecol. 1992;99,1004-7.

9. Spitz IM, Bardin CW, Benton L, Robbins A. Early pregnancy termination with Mifepristone and Misoprostol in the United Stated. New Eng J. Med 1998;338:1241-7.

10. Atrash HK, Strauss LT, Kendrick JS, Skjeldestad FE, Ahn YW. The relation between induced abortion and ectopic pregnancy. Obstetrics and Gynaecology. 1997;89(4):512-8.

11. GAM C et al, Reproductive outcome after medical and surgical abortion. International Journal Gynecol Obstet. 2008;87(9):713-8.

12. Schaff EA, Eisinger SH, Stadalius LS, Franks P, Gore BZ, Poppema S. Low dose Mifepristone 200 $\mathrm{mg}$ and vaginal Misoprostol for abortion, Contraception. 1999;59:1-6.

13. Schaff EA, Eisinger SH, Stadalius LS, Franks P. Vaginal Misoprostol administered at home after Mifepristone (RU 486) for abortion. J Fam Pract. 1997;44:353-60.

14. Mckinley C, Thong KJ, Baird DT. The effect of dose of Mifepristone and gestation on the efficacy of medical abortion with Mifepristone and Misoprostol. Hum Reprod.1993;8:1502-5.

15. Fiala V, Gemzel-Danielson K (2006) Review of medical abortion using Mifepristone in combination with a Prostaglandin analogue. Contraception. 2006;74(1):66-86.

16. Niinimaki et al. Complications of Medical and surgical abortion. Vol.114, no.4, October 20.

17. Sitruk Ware R. Mifepristone and Misoprostol sequential regimen side effects, complications and safety. Contraception. 2006;74:48-55.

18. Kahn JG, Becker BJ, Maclsaac L, et al. The efficacy of medical abortion: a meta-analysis. Contraception. 2000;61:29-40.

19. Virk J, Zhang J, Olsen J. Medical abortion and the risk of subsequent adverse pregnancy outcomes. New England Journal of Medicine. 2007;357(7):648-53.

20. Bouyer J, Coste J, Shojaei T. Risk Factors for ectopic pregnancy: a comprehensive analysis based on a large case - control, population based study in France. Am J Epidemiol. 2003;157:185-94.

21. Antonisamy B, Sivaram M, Richard J, Rao PSS: Trends in Intra-uterine Growth in single live births in Southern India. J Trap Pediatr. 1996,42:339-41.

22. Pinheiro A, David A, Joseph B: Pregnancy weight gain and its correlation to birth weight. Indian $\mathrm{J}$ Med Science. 2001;55:266-70.

23. Chen A, Yuan W, Meirik, O. Mifepristone induced early abortion and outcome of subsequent wanted pregnancy. Am J Epidemiol. 2004;160:110-7.

24. Jacky Boivin, Laura Bunting, John A Collins, Karl G Nygren. International estimates of Infertility prevelance and Treatment seeking: Potential need and demand for Infertility Medical Care. Hum. Reprod. 2007;22(6):1506-12.

Cite this article as: Sathe PA, Chaudhari KR, Parikh NS. Immediate complications and subsequent reproductive outcome after medical abortion: hospital based cross sectional study. Int J Reprod Contracept Obstet Gynecol 2015;4:1975-8. 